\title{
The Escape Room as evaluation method: A qualitative study of nursing students' experiences
}

\section{Abstract}

Purpose: Gamification or learning using game elements is a process that seeks to capture students' interest. One of the most popular games in recent years is the Escape Room, but the study of its use in education and with health professionals is still limited. The aim of this study was to find out the perceptions and experiences of final year nursing students in an Objective Structured Clinical Examination (OSCE) by means of an Escape Room.

Methods: In January 2019, 9 focus groups (FG) were held, with a total of 95 final year nursing students. We applied a qualitative content analysis approach and ATLAS.ti version 8 was used for data analysis.

Results: The data revealed 3 main themes and 8 sub-themes. The three main themes, which were mapped to the conceptual framework, were student learning outcomes, emotional impact on students and conclusions on the serious games experience. Both the main themes and the sub-themes were illustrated using representative quotes from the participants.

Conclusions: These results can help to apply these methodologies, such as the Escape Room, alongside other pre-existing ones, complementing the way in which students are assessed and the development of important nursing skills, such as teamwork and communication.

Keywords: simulation-based training; escape room; OSCE; gamification; nursing 


\section{Practice points}

- Nursing students prefer an evaluation system that promotes a relaxed environment such as the Escape Room does in comparison with OSCE.

- Nursing competences and skills must not be forgotten and are prompted with this kind of methodologies as results show. These competences include teamwork and communication skills, in addition to a realistic clinical environment.

- Gamification such as an Escape Room will promote student motivation in learning, critical thinking, thinking creatively and self-reflection.

\section{Introduction}

Gamification is a concept that has been used in various learning experiences for decades, and which does not only use games, but also different aspects and/or game elements geared towards completing a particular activity (Mackavey and Cron 2019). The gamification process also encompasses the use of reasoning games, as well as mechanical games, in a context that is primarily not intended for recreational-type games, with the intention of enthusing students and inviting them to participate in problem-solving related to the subject area (Gallegos et al. 2017; White and Shellenbarger 2018).

In this context, student-centred game-based learning has recently been used in various studies with the intention of increasing and fostering students' motivation, as well as 
improving the acquisition and retention of knowledge and skills (Milner and Cosme 2017; White and Shellenbarger 2018; Gómez-Urquiza et al. 2019), minimising stress and identifying students' strengths and learning opportunities (Adams et al. 2018).

The continuous progress that takes place in higher or university education calls for further investigation regarding its application in order to ascertain its effectiveness more comprehensively (Pront et al. 2018). However, and notwithstanding its apparent applicability in health sciences, availability of results in scientific literature is scarce. More specifically, several studies adapted for nursing students have been carried out, showing positive results in satisfaction, motivation, teamwork and learning (Cain 2019; Gómez-Urquiza et al. 2019; Mackavey and Cron 2019).

Since its inception in Japan in 2007, one of the most increasingly popular types of games has been the Escape Room (French 2015). In this game, the participants are given a scenario in which they must solve puzzles and use clues in order to complete the activity and thus leave or escape the room within a certain time frame (Adams et al. 2018; Connelly et al. 2018). However, there is a limited amount of studies which use this game with students and/or health professionals (Adams et al. 2018; Friedrich et al. 2018; Brown et al. 2019; Gómez-Urquiza et al. 2019), none of which, to our knowledge, have employed this game as an evaluation method. This adds a new value to learners' assessments where traditionally the established purpose of assessment was to describe the nursing's student abilities and skills required for a proposed clinical case, incorporating and adapting the student to professional learning environments (Helminen et al. 2016; Arribas-Marín et al. 2017). However, traditional evaluation methods such as the Objective Structured Clinical Examination (OSCE) approaches in a fragmentary and individual manner (Rebel et al. 2018) and therefore, with this new methods such as the Escape Room, the purpose of 
assessment includes to create and promote strategies and strengths to the students through solving activities and problems, self-reflection, coordination and communication in group (Connelly et al. 2018; Brown et al. 2019; Gómez-Urquiza et al. 2019).

The Escape Room as an evaluation method could assume particular importance given that Adams and collaborators (2018), Bani-issa and collaborators (2019) and Morrell and Ball (2019) mention several of its benefits, including reduction in stress, improved motivation, better identification of strengths and weaknesses, as well as providing the impetus to improve professional practice and make better performance decisions. All of this would provide an evaluation context in a safe environment for students, in which the OSCE should be developed. Furthermore, it has been shown that a student's academic performance could be hampered if they feel stressed, anxious, nervous or intimidated, potentially generating a negative perception of their attitude towards the OSCE as a consequence (Selim et al. 2012; Muldoon et al. 2014). In addition to this, various studies have shown that a nursing student's surroundings are important to them, as well as how the examiner interacts and communicates with them (Small et al. 2013; Jo and An 2014; Johnston et al. 2017).

The main objective of this study was thus to determine the perceptions and experiences of final year nursing students in an OSCE, by means of an Escape Room, designed as an evaluation method for a practical module involving an intermediate care hospital placement. 


\section{Methods}

\section{Design}

In January 2019, in order to meet the objective, a qualitative descriptive study was carried out with a phenomenological approach (Sandelowski 2000). The study was based on content analysis to explore students' experiences, viewpoints, perceptions and feelings regarding the use of the Escape Room as an evaluation method, incorporating innovative aspects in the evaluation context (Adams et al. 2018; Gómez-Urquiza et al. 2019), and applying the game experience during the performance within the OSCE. In this sense, the Escape Room provides a game context in a OSCE assessment of learning, using a standardized nursing intervention assessment check-list (Bulechek et al. 2018; Daniels and Pugh 2018). Although the aim of both methods is the same, OSCE and OSCE combined with the Escape Room, the main difference lays on the context within the evaluation itself where, according to our hypothesis, performance decisions could be improved.

\section{Setting}

The study was undertaken at the University of Almeria, a public university in the southeast of Spain (Andalusia), which offers a total of 32 university degrees, three of which belong to the health sciences branch: nursing, physiotherapy and psychology. Specifically, the study was carried out within the nursing degree, which has a duration of four academic years and equals 240 credits on the European Credits Transfer and Accumulation System (ECTS). 84 credits are accounted for by external placements distributed among several practical modules (Practicum I to VII): basic care, primary care, intermediate care and advanced hospital care. This study took place during Practicum V, which corresponds to the intermediate care hospital placement. The 
evaluation system of the Practicum consists of two parts: a progress report (60\%) from the clinical tutor and an OSCE (40\%) as assessment of learning overseen by a panel with two tutors. It is necessary to pass both parts in order to pass each module (Universidad de Almeria 2019).

The traditional OSCE entails individual assessment of a clinical case, like wound care procedures or intravenous medication administration or basic CPR, which is assessed through an ad hoc check-list based on standardized nursing interventions (Bulechek et al. 2018). However, the OSCE in combination with the Escape Room, lasting a maximum of 30 minutes, consisted of a group assessment (5 participants) in which they were confronted with various stations which included different clinical cases, part of a one entire case with the same patient through different clinical situations: wound healing, clinical safety, evidence-based decision making, primary clinical assessment based on the ABCDE method (Airway, Breathing, Circulation, Disability, Exposure), advanced cardio-pulmonary resuscitation and assistance in a multi-victim accident. During the resolution of the scenarios, lasting a maximum of 10 minutes in each scenario, the students obtained clues that were hidden in the material they had to use or aspects of assessing the patient (for example, a blue light for assessing pupil reactivity, finding a clue in the pupil of the simulator through blue light) that allowed resolution and access to the next station through the game-based experience. As it happens in the OSCE, students were evaluated by two examiners independently whilst they were performing clinical skills to solve the proposed clinical cases, using an ad hoc check-list based on standardized nursing interventions (Bulechek et al. 2018). For this purpose, a Likert scale was used from 0 to 4 individually for each case, where 0 meant "the intervention was not fulfilled" and 4 when "the intervention was fulfilled in an excellent manner", giving an overall assessment score (Table 1). 


\section{Participants and sampling}

The participants in the study were final year nursing students enrolled on Practicum V, who had previously experienced the traditional OSCE on other Practicums. Recruitment of participants, regardless of age or gender, took place during the development of the OSCE combined with the Escape Room. A total of 95 students agreed to participate in this qualitative study through focus groups. The inclusion criteria stipulated that participants were final year nursing students who had passed the previous Practicums and who had some previous experience of evaluation through the OSCE. Students with national and international mobility were excluded because of the variability of previous assessment systems they might have faced, as well as the potential language barrier.

\section{Data collection}

Data collection was carried out through 9 focus groups (FG), composed of 8 to 12 students. The FG allowed the participants to express their perceptions and experiences spontaneously and reflect on them, generating an exchange of ideas (Pedraz Marcos et al. 2014). A script for the focus groups was developed based on a literature review and interviews with recent graduates about the OSCE. The FGs took place on the same day as the Escape Room, had a duration of 50 to 60 minutes and were digitally recorded. The FGs would end when all the questions in the previously designed script had been answered in a detailed manner, and providing no new topic had emerged within the group. At the end of the session, a literal word-for-word transcription was created, identifying the interviewees with a "G" (group) and "P" (participants) and the number of participants, independent of their demographic data to guarantee anonymity. 


\section{Data analysis and credibility}

The data analysis was carried out through content analysis (Graneheim and Lundman 2004). Following transcription, an in-depth analysis was conducted, identifying reflection triggers (as meaning units), which were condensed and coded with labels. Codes with conceptual similarities were grouped into sub-themes. Similarly, sub-themes with conceptual similarities were grouped with each other (Figure 1). None of these subthemes was confined to a single major theme to avoid information bias. Each of the main themes was defined and illustrated with representative quotes from the participants. The ATLAS.ti software for Windows (version 8) was used for data analysis.

\section{INSERT FIGURE 1 AROUND HERE}

To ensure validity and thoroughness, content analysis was carried out independently by two researchers (CR, MR) and in case of doubt a third researcher (PR) was consulted. Likewise, the FGs were held by a moderator and an observer in order to record the expressions and non-verbal communication of the participants.

\section{Ethical considerations}

The study was approved of by the ethics committee of University of Almeria. Informed consent was obtained from all participants. Participants were provided with sufficient information concerning the objectives, methodology, voluntary nature of participation in the study, data confidentiality and the possibility of withdrawing from the study whenever they deemed appropriate. They were also informed that their participation and perceptions would in no way affect their evaluation. All the ethical principles of the Declaration of Helsinki were also considered. 


\section{Results}

A total of 95 final year nursing students took part in 9 FGs, meaning that the participation rate was $81,19 \%$ ( $\mathrm{N}=117$ final year students). The mean age of the participants was $20,76 \pm 4,77$ years (range 18-49). Most of the participants were women (72.63\%). A total of 8 sub-themes emerged from 3 themes (Table 2).

INSERT TABLE 2 AROUND HERE

\section{Student learning outcomes}

In general, the students found the dynamics of gamification through different scenarios interesting, as well as having to deal with potentially unknown aspects:

"The problem with the OSCE is that in the end you focus on one particular intervention, and here [Escape Room] you focus on various. At least you have an idea of several things and not just one intervention". G1-P3

"[...] One day you aren't going to be in a Practicum or an exam and we are going to be where we have been called to and we don't know what we are going to find or what is going to happen on that day or anything. So, I think that it is okay to have the attitude of "what is going to happen to me today?" And something like that could happen to you and it isn't going to be here, it is going to be in the hospital or in the street, you are going to find yourself in that situation and you have to know what to do [...]". G6-P6

In this vein, critical reflection emerged as one of the positive aspects for the development of those elements that could be improved upon by students: 
"The thing is we were always going to make mistakes in certain things, so the good thing about here [Escape Room] is that it helps you, those errors help you to learn, and for me that is, I don't know, for me those small things have helped me to learn more and in a different way." G9-P12

"[...] The mistakes we have made or what we have done, like I think they have stayed with me more... Because, for example in the OSCE I do know the mistakes I made, but I can't remember them when I have to repeat it, but this time I do go with that feeling...". G4-P7

Striking a balance between positive and negative experiences, the students identified one of the most important aspects of this methodology as the possibility to work in a group and strengthen their bond:

“[...] I was so nervous that I couldn't even do up my tunic [first test] and P7 helped me. Turned me around calmly and started to do it up, you know? And all these things mean a lot to me, right?" G2-P2

"[...] This is a system of working in a team, it is something that should be worked on a lot more in nursing, much more and it should be seen more in the practice... This collaboration has to be present... Nursing is nothing without teamwork". G3-P9

Communication was an element which was present in various sub-themes and was discussed extensively by the students. Being an indispensable element of teamwork, it was identified as an aspect that the Escape Room promotes:

“[...] In reality, in the future, we aren't going to be alone, rather we are going to need some help, advice or something, we are always going to depend on our team. This 
has also helped us to realise that we need to work much more in a team. We need to practise because (sometimes) we don't communicate at all." G8-P12

\section{Emotional impact on the student}

Based on students' perceptions, one of the most positively valued elements was the calmness with which they faced the experience:

"I didn't feel as if I was in an exam, to be honest. Not at all. I didn't think of it as an exam, far from it. I was comfortable and it didn't make me feel stressed or anything". G1-P8

"The positive that I take from this is the calmness that is not as stressful as in the OSCE. You don't have such a bad time. And so, probably the fact you are calm means that you get more involved with those processes and knowledge that, in the other way, you freeze and you can't give your best. However, if you are calmer and feel supported and so on, then you can." G5-P6

When the participants came to assess their perception of other evaluation methods, the sensation of a relaxed environment through gamification emerged as a positive aspect in contrast to the OSCE. Consequently, the difference in perceptions between both methodologies was revealed as a common factor amongst the participants:

"I really enjoyed it because I feel like I had more freedom than in an OSCE, where I say "I am doing it wrong, I am doing it wrong... ". I am always focussing on that, what I am doing wrong, and I freeze." G1-P5 
"[...] The OSCE is a surreal situation, you get really nervous, you start to do things that don't make sense, in the end it is more like you are following a guide in your head that doesn't make sense, and here you don't feel so observed". G2-P7

Similarly, students' motivation to improve as a result of the experience was another point of comparison between the two methodologies:

"[...] Whereas here [Escape Room] I want to find out more, to say "how infuriating I don't know how to do that, I want to know how'. Here is it like I want more, I want to know more. When the OSCE finishes I say "I failed that, it's frustrating I forgot it, I hadn't looked at that" and it is like an exam and nothing more, you forgot something and that's that." G6-P11

\section{Conclusions from the experience with serious games}

Moving on to aspects that could be improved upon, participants proposed the inclusion of serious games as a methodology in the practical seminars prior to the clinical or preclinical training period:

"I like it as an evaluation method, but I think it would be interesting to propose its use in Practicums, like to do pre-clinicals. Also, it is more entertaining when it comes to learning, not only as an exam but also as a class. It would be good to practise more like that, because later if we are evaluated in that way, we would be more prepared [...]." G4-P2

In this way, as well as providing practice for its use as an evaluation method, the participants also believed that it could be used to help strengthen other aspects of clinical skills needed in their training: 
“[...] I think that we could do this type of things as well instead of the pre-clinicals that we have to do, because you look a lot more prepared in the hospital. It happened to me today [today's situation] in the hospital in my placement, and I wanted to die. I realised that today, that I don't know how to react." G6-P12

To conclude, the students generally expressed a positive opinion towards participating in these types of activities with gamification aspects:

"[...] It has been a good experience. I have really enjoyed it. Fun, different, quite innovative and overall I liked it a lot". G7-P11

"The positive in coming here is that they evaluate you, but you also get to show off your knowledge in a way that you haven't had to study for, but rather you already have this knowledge and you have a good time". G5-P5

\section{Discussion}

The objective of this study was to determine the perceptions and experiences of final-year nursing students in an OSCE in combination with the Escape Room, designed as an evaluation system for a module of intermediate care hospital placements. After analysing the results, it was found that, as in previous studies (Small et al. 2013; Jo and An 2014; Johnston et al. 2017), an environment with gamification elements plays a key role in students' perceived level of nervousness. In this way, the results suggest that using methods such as the Escape Room, as opposed to the more traditional OSCE, helps to create a more relaxed atmosphere that, alongside working in a team, minimises stress levels and student frustration during the evaluation (Muldoon et al. 2014; Bani-issa et al. 2019; Morrell and Ball 2019) (Figure 2). This indicates that the complementary use of serious games can be a valid evaluation method which fosters a secure environment for 
the student and promotes the development of other skills that are also required in the profession, forming part of the nursing studies curriculum (Friedrich et al. 2018).

\section{INSERT FIGURE 2 AROUND HERE}

Likewise, this study supports and expands on existing knowledge regarding the use of methodologies, such as serious games, in the acquisition of clinical skills in disciplines such as nursing. Comparing the results of this study with other recent studies, such as Brown and collaborators' (Brown et al. 2019), teamwork emerged as the most identified element as a consequence of perceiving a relaxed environment. By encouraging teamwork in a particular way, this methodology provides the opportunity for each team member to show their knowledge, which, as the results suggest, is reinforced by a feeling of support from the group (Wu et al. 2018; Zhang et al. 2018; Gómez-Urquiza et al. 2019). Furthermore, in line with other studies on this type of scenario, the results reveal the promotion of critical thinking (Gómez-Urquiza et al. 2019) and thinking creatively (Adams et al. 2018; Connelly et al. 2018) for the development of group problem-solving.

Within this group setting the participants were able to identify communication as another skill which the Escape Room allowed them to develop, despite being an area where they observed the most difficulties and the most self-reflection took place. Notwithstanding the scarcity of studies on the subject, the use of serious games for the development of communication skills, as suggested by Brown and collaborators (Brown et al. 2019), has been shown to boost delegation skills, interdisciplinary collaboration and team rapport.

It is also important to highlight the importance of time management, a characteristic aspect of this type of serious game, as a beneficial element in the learning process. This element, alongside those previously discussed, such as teamwork and communication, 
enables the creation of a realistic environment or clinical situation. It is therefore important to consider the professional's response in situations where reaction time is vital in patient care, and also the necessity to provide support in maintaining concentration throughout the test (Brown et al. 2019; Gómez-Urquiza et al. 2019; Kinio et al. 2019). The results of this study are however inconsistent with this idea, mainly identifying the time element as something which fosters competitiveness.

In another level of results, special interest has been observed in the use of serious games as a teaching method, as well as an evaluation system. These results suggest the idea of including them in other disciplines, since they are enjoyable and a useful way of remembering and applying the acquired knowledge (Adams et al. 2018; Gómez-Urquiza et al. 2019). That being said, the results also shed light on participant's perspectives towards aspects of other evaluation methodologies, the OSCE being the main point of comparison for students, since it is currently one of the most used for the evaluation of knowledge and attitudes in simulated environments in an objective and balanced way (Beckham 2013; East et al. 2014). Moreover, and in spite of its preparation, higher costs and time-consuming previously, these innovative methodologies, the Escape Room in combination with the OSCE, add new values in order to help students to learn through the evaluation process. Notwithstanding the mistakes, students can repeat the interventions as many times as needed in the time given, and therefore allowing them to self-reflect and be full-aware of their own mistakes. In addition, students' performance is carried out in a context of realism, which allows them to feel safe, relax and comfortable rather than feeling of being evaluated.

Nevertheless, this study has various limitations. First of all, the study was carried out in a single institution, which could potentially limit the generalisation of its results. 
Nonetheless, several focus groups were conducted to ensure a representative sample of the target population. In this same line, as the focus groups were carried out only proximal to the event, it would be desirable to follow-up in time students' perceptions and retained knowledge. Secondly, literature on the use of serious games as an evaluation methodology is non-existent to our knowledge, which impedes the discussion of our results. Lastly, the investigation of perceptions was limited to nursing students and data collection time. Being a novel experience, it would have been interesting to explore the assessors' own perceptions in order to gain a deeper understanding of the use of these types of methodologies as evaluation methods in different subject areas and, on the other hand, to assess this new methodology in terms of reliability, utility and validity.

In summary, this study contributes to existing literature on the use of the Escape Room in the development of clinical skills in health sciences, namely its use as an evaluation method. This study establishes the basis for future investigations centred on the creation of an Escape Room that enables the development of communication skills, not just for the patient but also for the members of the health team, as well as using it to complement other evaluation methods in other subjects or combinations of subjects. The results also highlight potential barriers related to leadership, interdisciplinary work and competitiveness among professionals. Serious games can therefore encourage the development of the necessary skills for the future nursing professional that, as the results indicate, are not addressed by the other methodologies.

\section{Conclusion}

In conclusion, as suggested by the results of this study and based on recent investigations, the adoption of new teaching methodologies and evaluation systems such as serious games are an effective way of reinforcing nursing students' knowledge of clinical skills 
in different subjects, creating an atmosphere of relaxed gamification where motivation is the driving force for learning.

The Escape Room is a useful evaluation system which can complement other existing types of evaluation and the way in which students are assessed, as well as generate scenarios to develop other skills necessary for their professional career such as teamwork and communication, and encouraging realistic student performance given the secure and trustworthy environment. Similarly, this evaluation system has been shown to be useful for the integration of theoretical and practical knowledge.

\section{Notes on contributors}

Dr Pablo Roman, RN, MSc, PhD, holds the position of Vice Dean of Nursing within the Faculty of Health at University of Almeria and is leading the Teaching Innovation Group about Gamification in Health Sciences. In addition, he is participating in an International Innovation Group about clinical problem-based teaching and evidence-based practice.

Dr Miguel Rodriguez-Arrastia, $\mathrm{RN}, \mathrm{MSc}, \mathrm{PhD}$, is a 10 -year-expirence nurse and works as a lecturer in Nursing Degree at Jaume I University at the moment. His interests are in the learning environment and new technologies, evidence-based practice, elderly care and policies.

Dr Guadalupe Molina Torres, $\mathrm{PT}, \mathrm{MSc}, \mathrm{PhD}$, is a physiotherapist and bachelor in Sport Science. She currently works as a lecturer in Physiotherapy Degree at the University of Granada - Melilla Campus. Previous to this she worked as a physiotherapist in public hospitals.

Dr Verónica V. Márquez-Hernández, $\mathrm{RN}, \mathrm{MSc}, \mathrm{PhD}$, is an Assistant Professor at the Department of Nursing, Physiotherapy and Medicine, University of Almeria, Spain. She belongs to the Research Group for Health-Sciences CTS-451, Health Research Centre. She obtained a 
$\mathrm{PhD}$ in Health Sciences from University of Almeria. Her research interests include nursing education, new technologies, and chronic illness.

Dr Lorena Gutiérrez-Puertas, RN, MSc, PhD, is an Assistant Professor at the Department of Nursing, Physiotherapy and Medicine, University of Almería, Spain. She obtained a PhD in Health, Psychology and Psychiatry from University of Almería. Her research interests include nursing education and new technologies.

Dr Carmen Ropero-Padilla, $\mathrm{RN}, \mathrm{MSc}, \mathrm{PhD}$, is a nurse specializing in dementia care and is currently working as a lecturer in Nursing Degree at Jaume I University. Her research background and interests are in new methodologies about learning, elderly care and mistreatment of vulnerable groups.

Disclosure of interest: The authors declare no conflict of interests.

Funding: Partially funded by an Education Innovation Group Grant as part of the "Escape Room and clinical simulation: clinical evaluation based in games" Project within "Creation of Innovative and Good Teaching Practice in the University of Almeria Call. Biennium 2019 - 2020”.

Acknowledgement: The authors would like to acknowledge the assistance of Angela Daniel Vega of In Extremis Escape Room for her insightful comments and feedback on the direction of this study. We would also like to acknowledge those professionals for their support as part of the Directive Exchange Programme and Innovative and Good Practice Groups in Teaching at the University of Almeria. Biennium 2019-20.

Ethical approval: The study was approved of by the ethics committee of the University of Almeria. 


\section{References}

Adams V, Burger S, Crawford K, Setter R. 2018. Can You Escape? Creating an Escape Room to Facilitate Active Learning. J Nurses Prof Dev. 34(2):E1-E5. doi:10.1097/NND.0000000000000433.

Arribas-Marín J, Hernández-Franco V, Plumed-Moreno C. 2017. Nursing students' perception of academic support in the practicum: Development of a reliable and valid measurement instrument. J Prof Nurs. 33(5):387-395. doi:10.1016/j.profnurs.2017.03.001.

Bani-issa W, Al Tamimi M, Fakhry R, Tawil HA. 2019. Experiences of nursing students and examiners with the Objective Structured Clinical Examination method in physical assessment education: A mixed methods study. Nurse Education in Practice. 35:83-89. doi:10.1016/j.nepr.2019.01.006.

Beckham N. 2013. Objective Structured Clinical Evaluation Effectiveness in Clinical Evaluation for Family Nurse Practitioner Students. Clinical Simulation in Nursing. 9(10):e453-e459. doi:10.1016/j.ecns.2013.04.009.

Brown N, Darby W, Coronel H. 2019. An Escape Room as a Simulation Teaching Strategy. Clinical Simulation In Nursing. 0(0). doi:10.1016/j.ecns.2019.02.002.

Bulechek GM, Butcher HK, Dochterman J, Wagner CM. 2018. Nursing Interventions Classficiation (NIC). $7^{\text {a }}$ Ed. Madrid: Elsevier.

Cain J. 2019. Exploratory implementation of a blended format escape room in a large enrollment pharmacy management class. Curr Pharm Teach Learn. 11(1):44-50. doi:10.1016/j.cpt1.2018.09.010.

Connelly L, Burbach BE, Kennedy C, Walters L. 2018. Escape Room Recruitment Event: Description and Lessons Learned. J Nurs Educ. 57(3):184-187. doi:10.3928/0148483420180221-12.

Daniels VJ, Pugh D. 2018. Twelve tips for developing an OSCE that measures what you want. Med Teach. 40(12):1208-1213. doi:10.1080/0142159X.2017.1390214.

East L, Peters K, Halcomb E, Raymond D, Salamonson Y. 2014. Evaluating Objective Structured Clinical Assessment (OSCA) in undergraduate nursing. Nurse Education in Practice. 14:461-467. doi:10.1016/j.nepr.2014.03.005.

French S. 2015. The unbelievably lucrative business of escape rooms. MarketWatch. [accessed 2019 Mar 12]. https://www.marketwatch.com.

Friedrich C, Teaford H, Taubenheim A, Boland P, Sick B. 2018. Escaping the professional silo: an escape room implemented in an interprofessional education curriculum. J Interprof Care.:1-3. doi:10.1080/13561820.2018.1538941.

Gallegos C, Tesar AJ, Connor K, Martz K. 2017. The use of a game-based learning platform to engage nursing students: A descriptive, qualitative study. Nurse Educ Pract. 27:101-106. doi:10.1016/j.nepr.2017.08.019. 
Gómez-Urquiza JL, Gómez-Salgado J, Albendín-García L, Correa-Rodríguez M, González-Jiménez E, Cañadas-De la Fuente GA. 2019. The impact on nursing students' opinions and motivation of using a "Nursing Escape Room" as a teaching game: A descriptive study. Nurse Educ Today. 72:73-76. doi:10.1016/j.nedt.2018.10.018.

Graneheim UH, Lundman B. 2004. Qualitative content analysis in nursing research: concepts, procedures and measures to achieve trustworthiness. Nurse Education Today. 24(2):105-112. doi:10.1016/j.nedt.2003.10.001.

Helminen K, Coco K, Johnson M, Turunen H, Tossavainen K. 2016. Summative assessment of clinical practice of student nurses: A review of the literature. Int $\mathrm{J}$ Nurs Stud. 53:308-319. doi:10.1016/j.ijnurstu.2015.09.014.

Jo K-H, An G-J. 2014. Qualitative content analysis experiences with objective structured clinical examination among Korean nursing students. Japan Journal of Nursing Science. 11:79-86. doi:10.1111/jjns.12006.

Johnston A, Weeks B, Shuker M-A, Coyne E, Niall H, Mitchell M, Massey D. 2017. Nursing Students' Perceptions of the Objective Structured Clinical Examination: An Integrative Review. Clinical Simulation in Nursing. 13:127-142. doi:10.1016/j.ecns.2016.11.002.

Kinio AE, Dufresne L, Brandys T, Jetty P. 2019. Break out of the Classroom: The Use of Escape Rooms as an Alternative Teaching Strategy in Surgical Education. J Surg Educ. 76(1):134-139. doi:10.1016/j.jsurg.2018.06.030.

Mackavey C, Cron S. 2019. Innovative strategies: Increased engagement and synthesis in online advanced practice nursing education. Nurse Educ Today. 76:85-88. doi:10.1016/j.nedt.2019.01.010.

Milner KA, Cosme S. 2017. The PICO Game: An Innovative Strategy for Teaching Step 1 in Evidence-Based Practice. Worldviews Evid Based Nurs. 14(6):514-516. doi:10.1111/wvn.12255.

Morrell BLM, Ball HM. 2019. Can You Escape Nursing School?: Educational Escape Room in Nursing Education. Nurs Educ Perspect. doi:10.1097/01.NEP.0000000000000441.

Muldoon K, Biesty L, Smith V. 2014. 'I found the OSCE very stressful': Student midwives' attitudes towards an objective structured clinical examination (OSCE). Nurse Education Today. 34:468-473. doi:10.1016/j.nedt.2013.04.022.

Pedraz Marcos A, Zarco Colón J, Ramasco Gutiérrez M, Palmar Santos AM. 2014. Investigación cualitativa. Elsevier.

Pront L, Müller A, Koschade A, Hutton A. 2018. Gaming in Nursing Education: A Literature Review. Nurs Educ Perspect. 39(1):23-28. doi:10.1097/01.NEP.0000000000000251.

Rebel A, Hester DL, DiLorenzo A, McEvoy MD, Schell RM. 2018. Beyond the "E" in OSCE. Anesth Analg. 127(4):1092-1096. doi:10.1213/ANE.0000000000003317. 
Sandelowski M. 2000. Whatever happened to qualitative description? Research in nursing \& health. 23(4):334-40.

Selim A, Ramadan F, El-Gueneidy M, Gaafer M. 2012. Using Objective Structured Clinical Examination (OSCE) in undergraduate psychiatric nursing education: Is it reliable and valid? Nurse Education Today. 32:283-288. doi:10.1016/j.nedt.2011.04.006.

Small L, Pretorius L, Walters A, Ackerman M, Tshifugula P. 2013. Students' perceptions regarding the objective, structured, clinical evaluation as an assessment approach. Health SA Gesondheid.:1-8. doi:10.4102/hsag.v18i1.629.

Universidad de Almeria. 2019. Bachelor's Degree in Nursing. http://cms.ual.es/UAL/en/estudios/grados/grado1509.

White M, Shellenbarger T. 2018. Gamification of Nursing Education With Digital Badges. Nurse Educ. 43(2):78-82. doi:10.1097/NNE.0000000000000434.

Wu C, Wagenschutz H, Hein J. 2018. Promoting leadership and teamwork development through Escape Rooms. Med Educ. 52(5):561-562. doi:10.1111/medu.13557.

Zhang XC, Lee H, Rodriguez C, Rudner J, Chan TM, Papanagnou D. 2018. Trapped as a Group, Escape as a Team: Applying Gamification to Incorporate Team-building Skills Through an "Escape Room" Experience. Cureus. 10(3):e2256. doi:10.7759/cureus.2256.

Table 1. Assessed interventions and activities in one entire case using the Escape Room Table 2. Themes, sub-themes, number of extracts and representative quotes Figure 1. Array with thematic analysis from participants' responses in the focus groups Figure 2. Key assessment practices in an Escape Room in combination with OSCE 
Table 1: Assessed interventions and activities in one entire case using the Escape Room in combination with OSCE

\begin{tabular}{|c|c|c|}
\hline Assessed Interventions & Assessed Activities & Score \\
\hline \multirow{2}{*}{$\begin{array}{l}\text { Wound care in isolated environments } \\
\qquad(\approx 5 \text { students })\end{array}$} & Choose and use equipment for caring in isolation & $0-4$ \\
\hline & Use a evidence-based wound care procedure (e.g. TIME concept) & $0-4$ \\
\hline \multirow{2}{*}{$\begin{array}{l}\text { Evidence-based nursing practice in IV medication administration } \\
\qquad(\approx 5 \text { students })\end{array}$} & Literature research steps are carried out to find the best procedure & $0-4$ \\
\hline & Select and use the best procedure found & $0-4$ \\
\hline \multirow{6}{*}{$\begin{array}{l}\text { Primary evaluation in critical care } \\
\qquad(\approx 5 \text { students })\end{array}$} & Airway assessment & $0-4$ \\
\hline & Breathing assessment & $0-4$ \\
\hline & Circulation assessment & $0-4$ \\
\hline & Neurological Function assessment & $0-4$ \\
\hline & Exposure assessment & $0-4$ \\
\hline & Read an EKG & $0-4$ \\
\hline
\end{tabular}




\begin{tabular}{|c|c|c|}
\hline $\begin{array}{c}\mathrm{CPR} \\
(\approx 5 \text { students })\end{array}$ & Advanced CPR procedure & $0-4$ \\
\hline \multirow{3}{*}{$\begin{array}{l}\text { Assistance in multi-victim accidents } \\
\qquad(\approx 20 \text { students })\end{array}$} & Coordination in a big group & $0-4$ \\
\hline & Use of verbal and non-verbal communication & $0-4$ \\
\hline & Group leadership & $0-4$ \\
\hline & Total Score & $0-56$ \\
\hline
\end{tabular}


Table 1: Themes, sub-themes, number of extracts and representative quotes

\begin{tabular}{|c|c|c|c|}
\hline Main Theme & Sub-Themes & $\begin{array}{l}\text { Number of } \\
\text { extracts (n) }\end{array}$ & Representative quotes \\
\hline \multirow{3}{*}{ Learning outcomes } & Integrated clinical cases & 12 & $\begin{array}{c}\text { "Let's see, I think it was integrated, but above all [Life] Support was } \\
\text { integrated, I also think that is one of the things that we have forgotten, that } \\
\text { is what number } 2 \text { said [...]." G4-P8 }\end{array}$ \\
\hline & Critical reflection & 15 & $\begin{array}{l}\text { "[...] At least we reflected, and we realised that we went wrong. The bad } \\
\text { thing would be not to realise where we went wrong. And it did seem } \\
\text { realistic to me, to realise that we needed that collaboration and support." } \\
\text { G1-P1 }\end{array}$ \\
\hline & Teamwork & 46 & $\begin{array}{c}\text { "[...] It teaches you what it is really like to work in a team, although it was } \\
\text { chaotic in this case [...], but it is like how it will be in our placements, and } \\
\text { when we are actually working [...]." G5-P8 }\end{array}$ \\
\hline \multirow{2}{*}{$\begin{array}{c}\text { Emotional impact on } \\
\text { the student }\end{array}$} & Relaxed perception & 13 & $\begin{array}{c}\text { "[...] I came in with the impression that we were going to solve clinical } \\
\text { situations and since it was in a group, [...] I came in a lot calmer than I } \\
\text { probably would do in a normal OSCE. I prefer it." G7-P8 }\end{array}$ \\
\hline & Relaxed environment & 17 & $\begin{array}{l}\text { "I honestly think that I have done it [referring to the relaxed pressure-free } \\
\text { atmosphere], then later you think and you learn from the errors and that } \\
\text { you can learn more [...]." G2-P9 }\end{array}$ \\
\hline
\end{tabular}




\begin{tabular}{|c|c|c|c|}
\hline & $\begin{array}{c}\text { Motivation for the } \\
\text { students }\end{array}$ & 35 & $\begin{array}{l}\text { "[...] You went in knowing absolutely nothing and you had to do the best } \\
\text { you could. So I think that it wasn't something bad, it was actually quite } \\
\text { cool." G9-P10 }\end{array}$ \\
\hline \multirow{2}{*}{$\begin{array}{l}\text { Conclusions on the } \\
\text { serious games } \\
\text { experience }\end{array}$} & $\begin{array}{l}\text { Aspects of the Escape } \\
\text { Room that could be } \\
\text { improved upon }\end{array}$ & 6 & $\begin{array}{c}\text { "[...] How to shape this type of evaluation into what it really is, what it } \\
\text { asks of us as trainees and what we will end up being... Hopefully good } \\
\text { nurses [...]." G2-P5 }\end{array}$ \\
\hline & General evaluation & 30 & $\begin{array}{c}\text { "[...] I would encourage everyone who organised this to do it again, } \\
\text { because for me, personally, I really enjoyed it, I think that everyone did." } \\
\text { G8-P8 }\end{array}$ \\
\hline
\end{tabular}


Figure 1: Array with thematic analysis from participants' responses in the focus groups
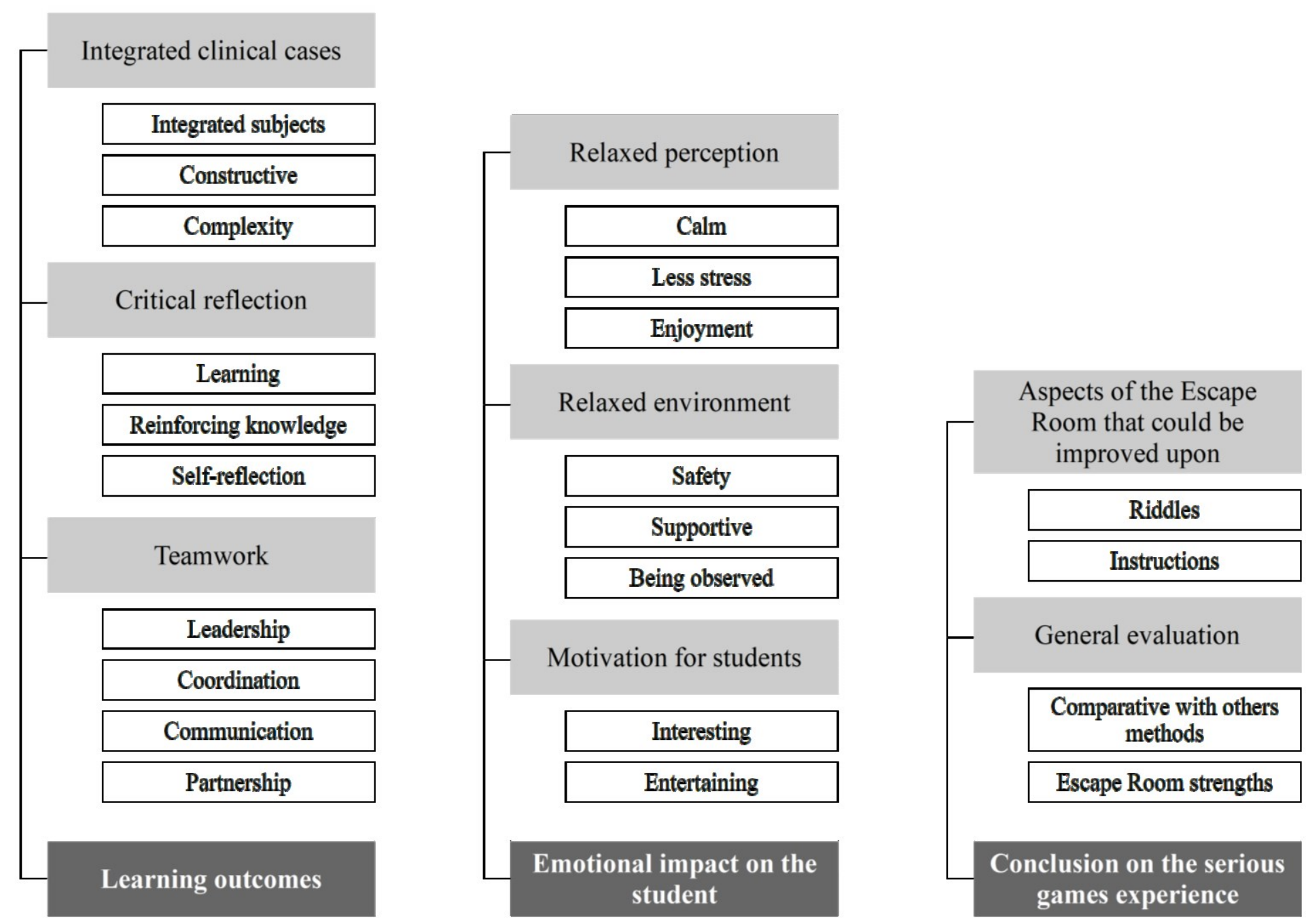
Figure 2: Key assessment practices in an Escape Room in combination with OSCE
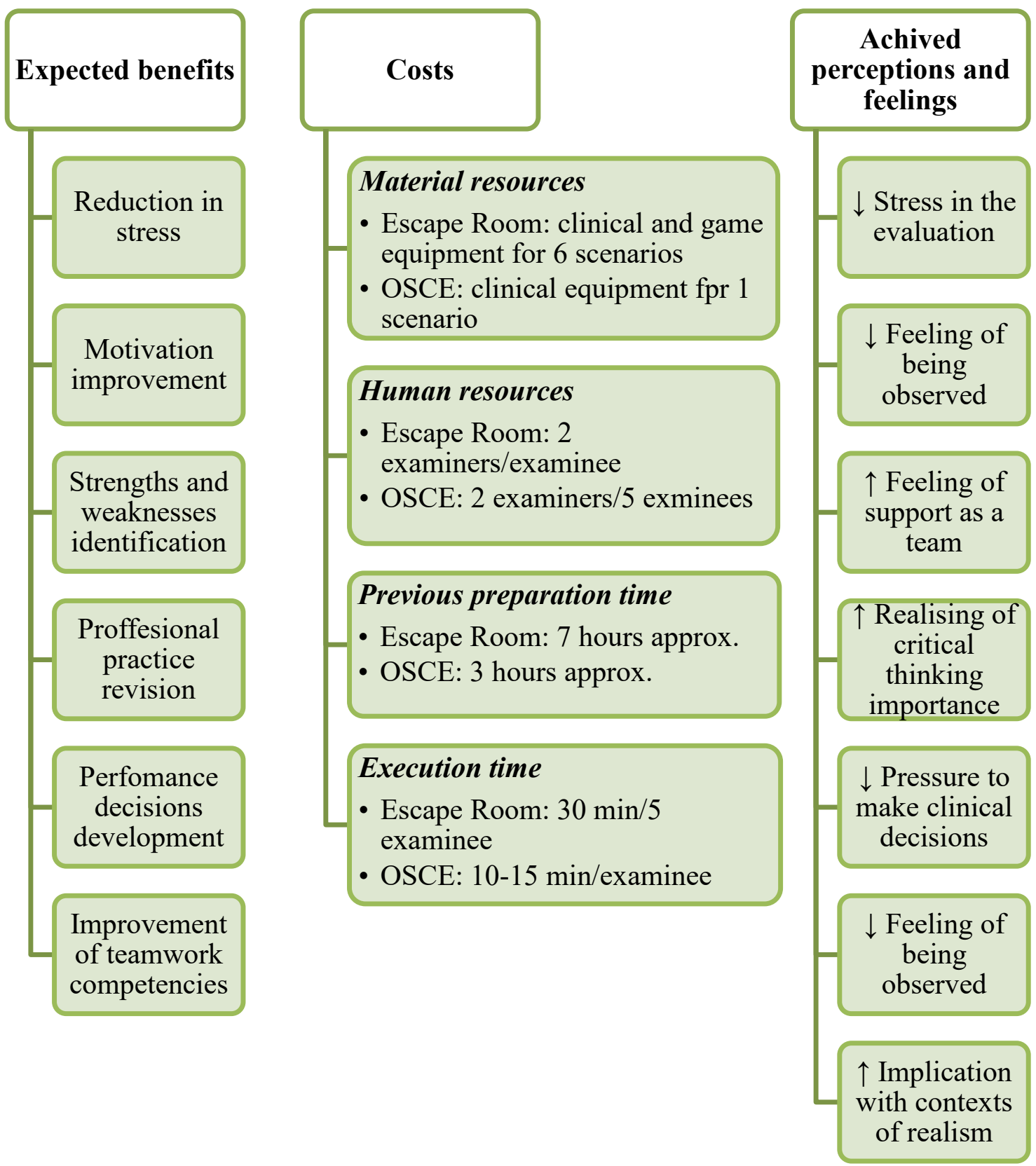